\title{
Urban and Industrial Metabolism: Towards Sustainable
}

\section{Planning}

\author{
$\mathrm{M}^{\mathrm{a}}$ Carmen Ruiz Puente and Elena Romero Arozamena \\ INGEPRO Research Group, Department of Transport and Technology of Projects and Process, University of Cantabria, Spain
}

\begin{abstract}
Nowadays, urban planning supposes a key issue to promote sustainable cities' development. In the last decades, the urban growth of developed countries has caused several environmental, social and economic problems, such as the inefficient use of resources and infrastructures. Notwithstanding, detailed analysis of population's necessities allows decreasing these drawbacks. These enhancements can foster a more feasible development through technical sustainability criteria. Therefore, the urban metabolism study becomes an essential tool to plan a suitable management for material and energy flows. Industrial Ecology (IE) theory looks for the sustainable integration of human activities on their natural environment. It seeks mimic natural systems performance and their processes. Industrial Metabolism (IM) studies those processes which turns material and energy into products and wastes. The IE final goals aim to promote improvements in process efficiency, decreasing consumption and waste generation through flows recirculation and exchange networks of material and energy. This contribution proposes a new conceptual framework which integrates urban and industrial metabolisms as an opportunity to achieve more efficient and sustainable development. The review of national and international experiences shows the improvements achieved through metabolisms' combination based on the exchanges of residual energy and water streams.
\end{abstract}

Key words: Urban planning, urban metabolism, industrial metabolism, industrial ecology, sustainable development.

\section{Introduction}

The cities are agglomerations of population which group services and infrastructures to improve the livability, quality of inhabitants' lives, health and social amenities, besides being a source of job and economic development. These conditions of social welfare encourage the emigration from areas less developed to consolidate great urban areas. Nowadays, the $50 \%$ of world population is gathered in urban areas. This value rises to $75 \%$ according to the population distribution in the developed countries [1]. Table 1 shows the cities size growth during the last century. The quantity of cities with more than 1 million of inhabitants in 2000 is 2.3 times more than 25 years before. Furthermore, this value raises to $75 \%$ considering only developed countries [1], Table 2

Corresponding author: $\mathrm{M}^{\mathrm{a}}$ Carmen Ruiz Puente, professor, research fields: industrial ecology, urban metabolism, sustainable urban systems. E-mail: ruizpm@unican.es. depicts the most populated urban areas in 2009 and their projection to 2025 [2].

Despite being a source of welfare and development, population centralization causes many effects at local and regional scale. The more populated areas the greater concentration of resource consumption and wastes generation, as well impacting negatively on environmental, social and economic aspects, such as some examples of Table 3. However, the urban planning makes possible lessen these effects from project's design phases. The consideration of these effects in the development of new areas or transformation of existing ones, allows more sustainable urban growth.

\section{Urban Sustainable Planning}

Traditionally, cities were expanded around down-town, but actually cities grow in complex way, due to the size, social structures, economic systems, geopolitical scene and technological development [5, 
6]. Nowadays the growth process combines the decentralization of business areas and their concentration in local communities [7]. This mechanism favors the urban impacts distribution, but these interventions are not trivial. The design of more environmental efficient urban areas is the main challenge of current urban planners [8]. These projects should find the consumption and waste generation decrease while the livability is kept or even improved. The advance towards more sustainable cities involves the suitable knowledge of physical, social, economic and politic environments. So, the land planning with the combination of technical and normative tools make that urban planning would be a suitable tool to face up this change.

\subsection{Urban Planning}

The model of a bad planned city is directly or indirectly changed by economic, social, scientific and cultural transformations [9]. The current land planning

Table 1 City-Size distribution in 1900-2000 (adapted from [2, 3]).

\begin{tabular}{|c|c|c|c|c|c|}
\hline & $>100.000$ & $>500.000$ & $>1.000 .000$ & $>10.000 .000$ & $>20.000 .000$ \\
\hline 1900 & 287 & 43 & 16 & 1 & 0 \\
\hline 1975 & Not estimated & 422 & 191 & 7 & 1 \\
\hline 2000 & 1.699 & 859 & 440 & 19 & 5 \\
\hline
\end{tabular}

Table 2 The 10 main urban areas of 2009 and projection 2025 [2].

\begin{tabular}{|c|c|c|c|c|c|}
\hline & Urban Area & Country & Population (2009) & Projected (2025) & Annual change \\
\hline 1 & Tokyo - Yokohama & Japan & 34.670 .000 & 35.295 .000 & $0.11 \%$ \\
\hline 2 & Jakarta & Indonesia & 23.345 .000 & 34.090 .000 & $2.39 \%$ \\
\hline 3 & New York & United States & 21.295 .000 & 22.785 .000 & $0.42 \%$ \\
\hline 4 & Mumbai, MAH & India & 20.400 .000 & 27.440 .000 & $1.87 \%$ \\
\hline 5 & Manila & Philippines & 20.075 .000 & 29.285 .000 & $2.39 \%$ \\
\hline 6 & Delhi, DEL & India & 19.830 .000 & 27.220 .000 & $2.00 \%$ \\
\hline 7 & Seoul - Incheon & South Korea & 19.660 .000 & 19.815 .000 & $0.05 \%$ \\
\hline 8 & Sao Paulo & Brazil & 19.505 .000 & 21.860 .000 & $0.71 \%$ \\
\hline 9 & Mexico City & Mexico & 18.585 .000 & 20.295 .000 & $0.55 \%$ \\
\hline 10 & Osaka - Kobe - Kyoto & Japan & 17.310 .000 & 17.395 .000 & $0.03 \%$ \\
\hline
\end{tabular}

Table 3 Negative effects of urban areas (adapted from [3 and 4]).

\begin{tabular}{|c|c|c|c|c|}
\hline \multirow{15}{*}{ 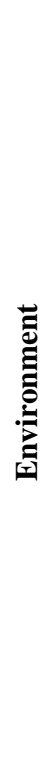 } & & Resource consumption & \multirow{4}{*}{ 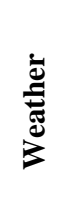 } & Thermal inversion and microclimate change \\
\hline & \multicolumn{2}{|c|}{ Landscape degradation, coast and forest } & & $\begin{array}{c}\text { Residual heat emission, temperature increase and } \\
\text { solar radiation reflection. }\end{array}$ \\
\hline & \multirow{5}{*}{ 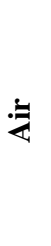 } & Air polluted dome creation & & Heat islands creation \\
\hline & & $\mathrm{CO}_{2}, \mathrm{CO}, \mathrm{SO}_{2}$, dust emissions & & Cloudiness, fog and rainfall increase \\
\hline & & Photochemical smog & \multirow{8}{*}{ ) } & Transport problems \\
\hline & & Evapotranspiration decrease & & Town-planning degradation \\
\hline & & Atmospheric humidity decrease & & Immigration not integrated \\
\hline & \multirow{5}{*}{ 冚 } & Water consumption increase & & Problems with social integration \\
\hline & & Polluted coastal water & & Marginalization and delinquency \\
\hline & & Sewage dump & & Ageing of down-town \\
\hline & & Solid wastes leaching & & Outskirts degradation \\
\hline & & Rivers' courses and streams changes & & Noise generation \\
\hline & \multirow{3}{*}{ "ृ̈ } & Imperviousness and landslide increase & \multirow{3}{*}{ 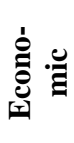 } & Industries collocation \\
\hline & & Solid waste dumping & & Services more expensive \\
\hline & & Soil roughness and quality change & & Urban speculation \\
\hline
\end{tabular}


inherits previous defects of environmental harmful politics. Therefore, the suitableness of urban planning politics towards ecological fundamentals, encourage the orientation to more environmental friendly behaviors [10].

The current urban planning combines different scopes to improve the inhabitants' conditions of life with less impacts generation. The scientific-technical scope let built amenities and infrastructures from limited resources. The artistic scope adapts urban planning to aesthetic, comfortable and livable environment. And the public field tries to integrate the plurality of views of different social groups, as well the conservation of natural areas [11].

Town planning has five work fields based on areas' functionality: housing, economic activities, social amenities (cultural, sport, health, etc.), green areas and transport. Despite each planning field has their own characteristics, the previous scopes should be considered. The recognition of these fields favors specific analysis about inhabitants' needs and the support of the design on technical and artistic scopes [11]. However, the current development needs new strategies in planning patterns, as the strategic evaluation or projects' environmental integrity [12]. According to these guidelines, this paper aims to show an integration scope in this way to sustainable planning.

\subsection{Urban Metabolism}

According to Newman [13], the tendency of urban studies to solve sustainably environmental problems is supported in the characterization of the city as an ecosystem. This idea is develop by the interdisciplinary field of Urban Ecology (UE). This emergent area tries to understand how the human and ecologic processes can coexist inside the human-made systems and helps more sustainable societies' development [14]. The eco-systemic approach entails the city observation as a whole, and its material and energy flows study. The evaluation of system inputs and outputs allows the assessment of improvements, such as resource use efficiency, energy conservation, or waste reuse. This favors the management system planning and city integration in natural processes (Fig. 1).

The cities are open and dissipative systems, in other words, they depend on material and energy inputs from the environment, but consequently this increases the environment's disorder [4]. The urban metabolism model describes and analyses material and energy flows which circulates through city's system. This concept rise firstly in 1965 with the publication of A. Wolman "The metabolism of the city" in Scientific American; where the author resembles the urban ecosystem operation like a metabolic process [15]. The metabolic study quantifies flows and stocks, evaluates social, economic and environmental effects from their circulation, and controls their impacts through different strategies as dematerialization, closing loops or energy and material sources substitution [16]. Some kind of practical studies even distinguishes the endosomatic and exosomatic metabolism. The first concept is related with the material and energy consumed as food and drink by the population. But cities need other ways of energy. The exosomatic metabolism assesses the material and energetic flows used in buildings, transport, industrial operations, water supply, lighting or heating [4]. So, the urban metabolism could be defined as the sum of total of the technical and socioeconomic processes that occur in cities, resulting in growth, production of energy, and elimination of waste [5].

Notwithstanding, these static evaluations should be complemented with the consideration of several dynamic aspects such as population changes, urban structure modification or distortion of physical and social conditions. Therefore, the urban metabolism studies are used to identify environmental problems such as resource use, pollution or efficiency; and also as analytical tools to support the decision-making processes $[17,18]$. 


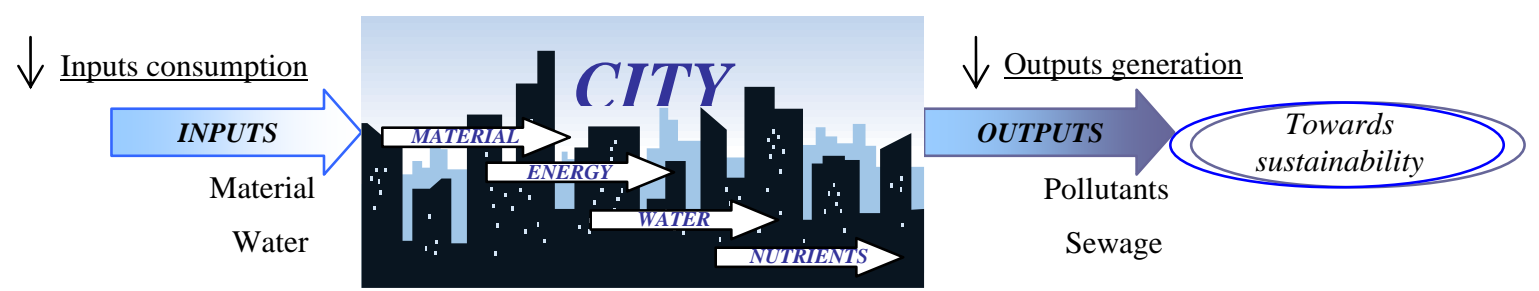

Fig. 1 Urban metabolism.

\section{City and Industry}

\subsection{Industry Role in Urban Evolution}

The industrial activity is source of society's economic development. The businesses and fabrics creation encourages the local job, favors new economic activities localization and consequently attracts new population to the urban areas. Traditionally, the industrial prosperity has associated a simultaneous urban growth. However, the industrial role has been described by two opposed perspectives: promoter of urban development and urban planning disturbing [19].

Massive industrial setting on limited urban landscape caused cities collapse at the end of the 18th century [9]. New industrial activities were set over existing and limited urban landscape. The infrastructures were unable to support the labor and pre-industrial urban structures collapsed. The industrial activity geared towards more productive operation worsens the conditions of life and makes necessary the governmental intervention. In Spain, the Adapted Text about Soil use Law in 1976 promotes the urban plans which separate industries from cities. However, the industrial soil rezoning caused speculation. The deserted industrial areas in the cities became profitable plots to built housing near to town centre, while the excess of new plots sought investors out of their municipality causing competition [9]. Consequently, this caused a lack of order in many town centres as well as great percentage of desert industrial plots.

Nowadays, the integral urban regeneration should consider a combined soil uses, and also be supported on a diversified economic base where the industry is a source of cohesion and wealth distributor.

\subsection{Industrial Ecosystem}

Industrial Ecology (IE) is the science that studies the industrial sector in a systemic way and compares its operation to the ecosystems' processes. As UE origin, the publication in 1989 of "The industrial ecosystem view" in Scientific American by R. Frosch and N. Gallopoulus promoted the interest in IE. This discipline analyses the dynamic relationships between industry and environment, based on the sustainable integration of the productive activities in its environment [20-22]. Industrial areas, as well as urban areas, are objective of the analytical model of metabolism, named in this case Industrial Metabolism (IM) [13]. Industrial Metabolism is the practical method to evaluate through input-output analysis the flows which circulates among the economic processes, from the resource extraction and goods and services production, to the waste disposal [23, 24]. Frosch [25] considers the material flows (even water), energy, economic capital, labor and information as the essential flows to assess the consumption and productions systems (Fig. 2).

Economic activities follow lineal patterns of resources consumption, goods manufacture and services offer, use, disposal and impacts generation (grey boxes of Fig. 3). Notwithstanding, the IE suggests the setting of strategies which improves their efficiency through the closing loops of material and energy, and the byproducts exchanges, both supported on the analytical flows evaluation. The practices introduction (green boxes Fig. 3), as repair, recycle or recovery, allow material flows reuse [26]. The Industrial Symbiosis (IS) is another strategy to close the loops. The IS establishes collaboration relationships to flows exchange. The creation of 

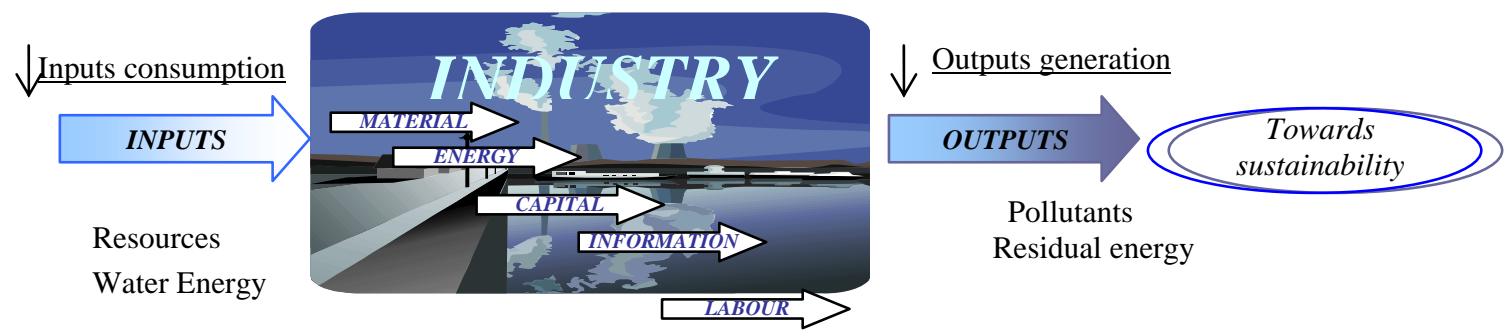

Pollutants

Residual energy

Fig. 2 Industrial metabolism.

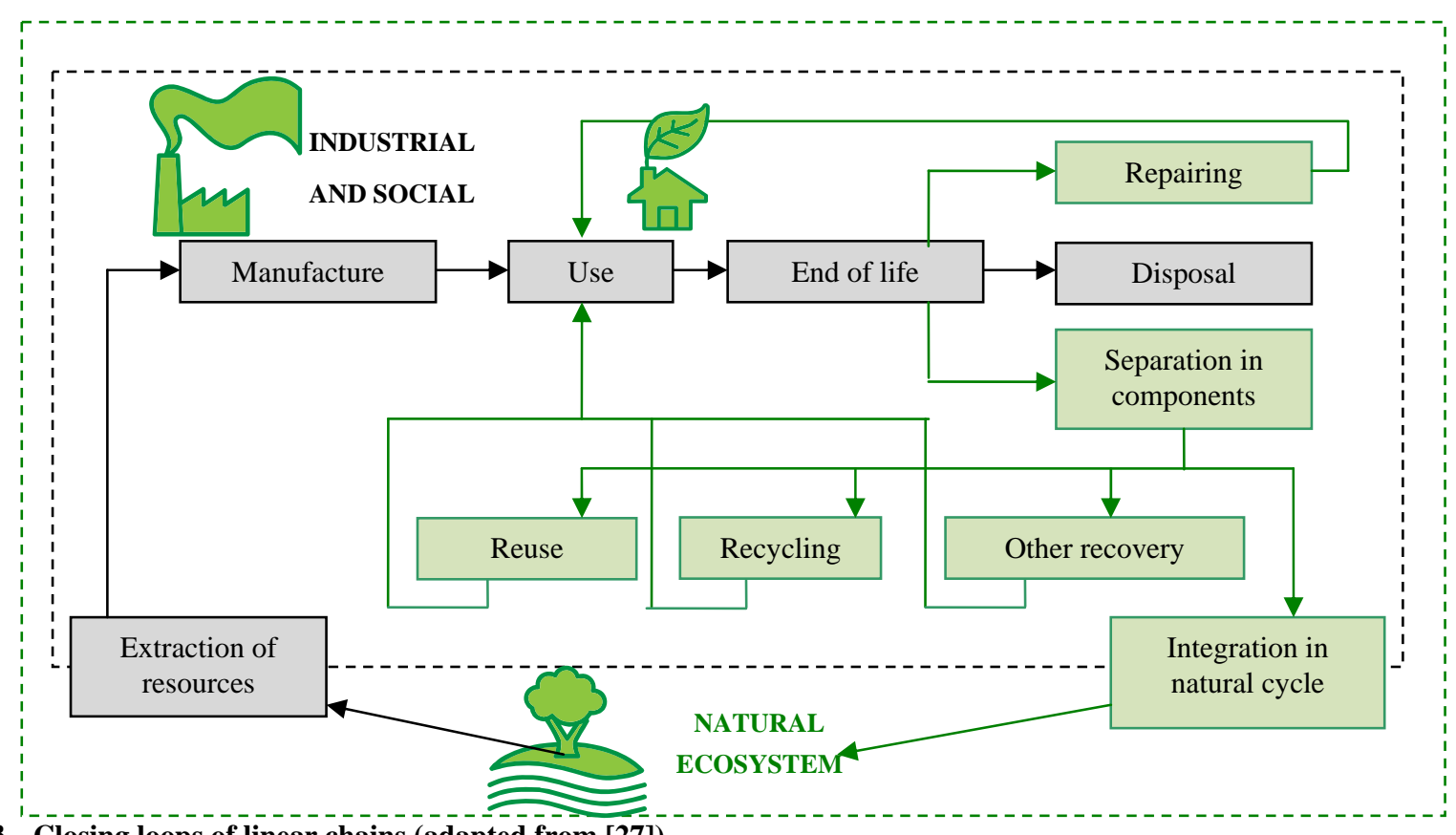

Fig. 3 Closing loops of linear chains (adapted from [27]).

networks to exchange materials and energy between businesses makes easier the decrease of resource consumption and wastes generation, and therefore increase their efficiency.

\section{Metabolism Combination}

Sustainable urban planning models relate varied disciplines. Some innovative models combine typical industrial methodologies, such as energy and material flows analysis (EMFA), and strategies of Industrial Symbiosis [12]. This paper aims to show the possibility to integrate the metabolic urban and industrial performance besides different methodologies. This global view supported in metabolism analysis, is possible combine these systems to get more efficient group.
The study of metabolisms provides the qualitative and quantitative data of system's flows. The qualitative data comparison shows that material, water and energy flows coexist in both systems. This allows the creation of symbiotic relationships between industry and city system, which encourage systems' cohesion and their environmental friendly integration.

So, considering that urban planning is a multidisciplinary field and the similarities of their residual flows, metabolism analysis gears the combination of urban and industrial systems to achieve more efficient operation. However, despite of the three flows coexistence, the creation of energy and water networks is more feasible due to the data availability and accessibility. Three European experiences have been selected to illustrate the urban-industrial symbiosis implantation. 
Kalundborg (Denmark). It is the most relevant example of industrial integration at great scale [24]. The cooperative network is formed by seven geographically closed enterprises and the municipality of Kalundborg. The relationships' philosophy exploits waste flows and byproducts on a commercial basis [28]. The businesses exchange byproducts from their processes, while the urban wastes are used to generate biogas and compost to soil regeneration. The power plant supplies electricity and steam to the municipality for district heating, this substitutes the conventional houses boilers. About water stream, urban sewage are treated and circulated in cascading among the industrial complex.

Gothenburg (Sweden). The second most important city of Sweden (510.000 inhabitants) has a district heating system of more than $400 \mathrm{~km}$, whose particular sources are: the heat from the waste incineration plant in Sävenäs, waste heat from Shell refineries, heat from heat pumps at the Rya sewage treatment works, heat from the truck engine testing facility at the Volvo Truck Manufacturing Plant, and heat from Chalmers University research facility for fluidized bed [24]. These non conventional heating sources supply the $60 \%$, percentage completed with sources as biofuels, natural gas or geothermic energy [29]. The heat sources are managed by a control system which extracts heat from the most convenient source.

Joensuu (Finland). The energetic system supply in Joensuu (50.000 inhabitants) can supply the necessary heat to industrial processes and district heating, besides supply the $66 \%$ of local electricity demand. The cogeneration power plant Sirkkala avoids external fuel consumption through the use of waste materials and renewable local material, such as peat and forestalls wastes [30].

\section{Conclusions}

The introduction of more environmental friendly strategies in urban planning allows gearing the city's performance towards more sustainable behaviors. The analysis of urban metabolism identifies and quantifies the system's flows, and makes easier the proposal of action plans which increase the consumption efficiency and pollution decrease. The metabolic model extension offers the opportunity to combine urban and industrial systems through flows' exchange and closing loops. International and national experiences show the practical application of this proposal. The diversification of energetic, water and material sources achieves more flexible systems which adapt themselves towards external impacts, such as economic crisis or resources scarcity. The development of these activities, such as symbiosis and reuse, increases the efficiency of human-made systems and achieves the sustainable integration on their natural environment.

\section{References}

[1] Population Reference Bureau, 2009 world population reference data sheet, available online at: http://www.prb.org/pdf09/09wpds_eng.pdf.

[2] Demographia World Urban Areas \& Population Projections (5th Comprehensive Edition), 2009. http://www.demographia.com/db-worldua2015.pdf.

[3] B. J. J. Berry, Urbanization, in: J. M. Marzluff, E. Schulenberger, W. Endlicher, M. Alberti, G. Bradley, C. Ryan, C. ZumBrunnen and U. Simon (Eds.), Urban Ecology: An international perspective on the interaction between humans and nature, Springer Scienci+Business Media, LLC, New York, 2008.

[4] J. Terradas, Ecología Urbana, Edit, Rubes Editorial, Barcelona, 2001. (in Spanish)

[5] C. Kennedy, J. Cuddihy and J. Engel Yan, The changing metabolism of cities, Journal of Industrial Ecology 11 (2007) 43-59.

[6] P. Hall, Cities in Civilization, Edit. Pantheon, New York, 1998.

[7] E. W. Burgess, The growth of the city: An introduction to a research project, in: J. M. Marzluff, E. Schulenberger, W. Endlicher, M. Alberti, G. Bradley, C. Ryan, C. ZumBrunnen and U. Simon (Eds.), Urban Ecology: An international perspective on the interaction between humans and nature, Springer Scienci+Business Media, LLC, New York, 2008.

[8] S. Pauleit and F. Duhme, Assessing the environmental performance of land cover types for urban planning, Landscape and Urban Planning 52 (2000) 1-20. 
[9] G. Ponce and F. J. Martínez, Industria y ciudad: entre la aceptación y el rechazo de una relación histórica (in Spanish), Investigaciones geográficas 25 (2001) 67-94.

[10] V. Bettini, Elementos de ecología urbana, Edit. Trotta, Madrid, 1998. (in Spanish)

[11] I. Sánchez de Madariaga, Introducción al urbanismo: conceptos y métodos de la planificación urbana, Edit. Alianza, Madrid, 1999. (in Spanish)

[12] N. Niwa, Industrial ecology as an instrument for innovative spatial planning, in: Proceedings of International Federation for Housing and Planning World Congress, Copenhagen, Denmark, Sept. 23-26, 2007.

[13] P. W. G. Newman, Sustainability and cities: Extending the metabolism model, Landscape and Urban Planning 44 (1999) 219-226.

[14] J. M. Marzluff, E. Schulenberger, W. Endlicher, M. Alberti, G. Bradley, C. Ryan, C. ZumBrunnen and U. Simon, An introduction to Urban Ecology as an interaction between humans and nature, in: J. M. Marzluff, E. Schulenberger, W. Endlicher, M. Alberti, G. Bradley, C. Ryan, C. ZumBrunnen and U. Simon (Eds.), Urban Ecology: An International Perspective on the Interaction between Humans and Nature, Springer Scienci+Business Media, LLC, New York, 2008.

[15] Y. Zhang, Z. Yang and X. Yo, Ecological network and emergy analysis of urban metabolic systems: Model development and a case study of four Chinese cities, Ecological Modelling 220 (2009) 1431-1442.

[16] C. Hendriks, D. Müller, S. Kytzia, P. Baccini and P. Brunner, Material flow analysis: A tool to support environmental policy decision making-Case-studies on the city of Vienna and the Swiss lowlands, Local Environment 5 (3) (2000) 311-328.

[17] E. H. Decker, S. Elliott, F. A. Smith, D. R. Blake and F. S. Rowland, Energy and material flow through the urban ecosystem, Ann. Rev. Energy and Environment 25 (2000) 685-740.

[18] S. Niza, L. Rosado and P. Ferrao, Urban Metabolism: Methodological advances in urban material flow accounting based on the Lisbon case study, Journal of Industrial Ecology 3 (3) (2009) 384-405.
[19] G. Ponce, Nuevos procesos de localización industrial, planeamiento urbano y calidad de vida, Industria y medio ambiente Dpto. Geografía Humana, AGE (2000) 199-208. (in Spanish)

[20] E. A. Lowe and L. K. Evans, Industrial ecology and industrial ecosystems, Journal of Cleaner Production 3 (1-2) (1995) 47-53.

[21] T. E. Graedel and B. R. Allenby, Industrial Ecology, Edit. AT\&T Pearson Education, Inc., New Jersey, USA, 2003.

[22] J. Ehrenfeld, Industrial ecology: A new field or only a metaphor? Journal of Cleaner Production 12 (2004) 825-831.

[23] D. L. Rigby, Regional dynamics and industrial ecosystems: An introduction, in: M. Ruth and B. Davidsdottir (Eds.), The dynamics of regions and networks in industrial ecosystems, Edward Elgar Limited, Glos (UK), 2009.

[24] N. Munier, Introduction to sustainability: Road a better future, Edit. Springer, Dordrecht, 2005.

[25] R. A. Frosch, Sustainability engineering, The Bridge 29 (1) (1999) 2-3.

[26] R. Lifset, Closing the loop and honing our tools, Journal of Industrial Ecology 5 (4) (2001) 1-2.

[27] M. C. Ruiz, E. Romero and I. Fernández, Eco-industrial parks' operation design: Influential factors, in: Proceedings of II International Conference on Sustainability Measurement and Modelling, Barcelona, Nov. 5-6, 2009.

[28] Industrial Symbiosis. Industrial Symbiosis, sharing of resources, available online at: http://www.symbiosis.dk/industrial-symbiosis.aspx.

[29] C40 Cities, Gothenburg, Sweden, Waste to energy cuts 200.000tCo2 annually in Gothenburg, available online at: http://www.c40cities.org/bestpractices/waste/gothenburg _system.jsp.

[30] J. Korhonen, H. Niemelaïnen and K. Pulliainen, Regional industrial recycling network in energy supply: The case of Joensuu city, Finland, Corporate Social Responsibility and Environmental Management 9 (2002) 170-185. 